\title{
Distraction effects of navigation and green-driving systems - results from field operational tests (FOTs) in the UK
}

\author{
Andrew Morris $^{1}$ (i) $\cdot$ Steven Reed $^{1} \cdot$ Ruth Welsh $^{1}$. \\ Laurie Brown $^{1} \cdot$ Stewart Birrell ${ }^{2}$
}

Received: 24 February 2015 / Accepted: 21 July 2015 /Published online: 31 July 2015

(C) The Author(s) 2015. This article is published with open access at SpringerLink.com

\begin{abstract}
Introduction Navigation systems and green-driving advisory systems are now a common feature in modern vehicles. The interaction of drivers with such systems when driving must be considered to minimise distraction whilst maintaining the benefits provided. This research investigates the glance behaviours of drivers, assessed from video data, when using a navigation device (study 1) and a green-driving advisory device (study 2). The main research question addressed was 'Does the device cause visual distraction that might be detrimental to safety?' The main focus was to establish the number of glances of $2 \mathrm{~s}$ or more to the systems and relate this to driver safety (as stipulated in new guidelines for use of invehicle systems proposed by the National Highway Traffic Safety Administration (NHTSA) in the US).

Methods Study 1 tested a Blom Ndrive G800 navigation device whilst study 2 tested the Foot-LITE device; a Smart' driving system which incorporates Green Driving Support (GDS). In study 1 , the subjects were specifically requested to drive a prescribed route of approximately $25 \mathrm{~km}$ and were directed by an experimenter who was present in the front passenger seat (baseline condition phase). After approximately 8 months, the same 10 subjects were requested to perform the same drive but using the navigation device to guide them around the route (experimental condition phase). In study 2, all subjects were asked to drive a prescribed route first without using the Foot-LITE device (baseline condition phase) and
\end{abstract}

Andrew Morris

a.p.morris@lboro.ac.uk

1 Loughborough University Design School,

Loughborough, Leics LE11 3TU, UK

2 University of Warwick, Coventry, UK then some days later, with the Foot-LITE device (experimental condition phase).

Results In study 1, the percentage of eyes off road time for drivers was much greater in the experimental (with device) condition compared to the baseline condition $(14.3 \%$ compared to $6.7 \%$ ) but whilst glances to the navigation device account for the majority of the increase, there are very few which exceed $2 \mathrm{~s}$. Drivers in study 2 spent on average $4.3 \%$ of their time looking at the system, at an average of $0.43 \mathrm{~s}$ per glance; no glances exceeded $2 \mathrm{~s}$.

Conclusions In study 1, whilst glances to the personal navigation device account for the majority of the increase in eyes off road time (in accordance with intuitive expectations), when the durations of the glances are analysed, there were very few which are $2 \mathrm{~s}$ or more in duration. The average glance was $0.76 \mathrm{~s}$ which compared with average duration of glances to other target areas of $0.6 \mathrm{~s}$, well below the proposed NHTSA guidelines. In study 2, the main outcome was that the total number of glances made was similar for each condition, at approximately 1100 . Therefore glances to the in-vehicle Smart driving system during the experimental condition must have been reallocated from a different location. Around $75 \%$ of the glances were between 0.2 and $0.6 \mathrm{~s}-$ also well below the NHTSA proposed guidelines. The results of the study have important design implications for future in-vehicle information systems.

Keywords Driver distraction · Eyes-off-road-time · Glance behaviour $\cdot$ Green driving advisory system $\cdot$ Navigation device

\section{Introduction}

Little is known about the manner in which drivers interact with new technologies in vehicles. Many such technologies 
are thought to increase the risk of driver distraction since they may increase the likelihood that the driver will take his or her "eyes off the road" during the driving task and hence not focus on the traffic conditions (i.e., become 'distracted') thereby increasing the crash-risk. In this study, 'eyes-off-road' is defined as any point during driving at which the visual attention is diverted away from the road towards the vehicle interior or mirrors. Hedlund [1] provides a useful definition of distraction; he defines it as being "a diversion of attention from driving, because the driver is temporarily focusing on an object, person, task or event not related to driving, which reduces the driver's awareness, decision making ability and/or performance, leading to an increased risk of corrective actions, near-crashes, or crashes".

Many recent studies have looked at the effect of distraction on crash risk [2-4] although distraction is not a new problem in road safety - it has been around for as long as people have been driving cars [5]. However, there is increasing evidence that driver distraction is one of the major contributing factors to car and truck crashes and incidents $[2,6]$ and it is likely that the problem will increase as more and more advanced technologies and informatics find their way into vehicles. In response, there has been a recent explosion in research on this topic [7]. Many studies have looked at the overall effects of distraction on crash-risk. NHTSA [8] in the US estimated that at least $25 \%$ of crashes involve some form of distraction whilst other studies indicate that the rate of crash-involvement amongst distracted drivers might be as high as $35-50 \%[9,10]$ the former relates to the likelihood of distraction when a crash occurs whereas the latter considers the risk of accident when distraction is known to have occurred. An important reference is Klauer et al. [2] who, using data from the 100-car study, found that whilst short, brief glances away from the forward roadway for the purpose of scanning the driving environment are safe, glances totalling more than $2 \mathrm{~s}$ for any purpose increase near-crash/crash risk by at least two times. This important research based on video evidence collected from naturalistic driving studies forms the basis of new proposed guidelines generated by NHTSA [11] which includes a recommended set of criteria that manufacturers are expected to use to ensure the systems or devices they provide in their vehicles do not distract the driver with tasks not directly relevant to safely operating the vehicle. One of the guidelines states that in-vehicle information systems (IVIS) manufacturers should ensure that the design of the IVIS should be such that it limits individual off-road glances required for device operation to be no more than $2 \mathrm{~s}$ in duration which is in accordance with Klauer's research. This sound evidence-base has been used as a benchmark for some of the analysis described later in this paper.

The issue of driver distraction has been the focus of several consortia of researchers, government agencies, and automotive manufacturers in recent years. Some of the work has been directed at the need to evaluate in-vehicle information systems and their effect upon visual performance, particularly as use of them has been predominantly unregulated since they were first introduced. Relevant to this particular study, NHTSA has been proposing a set of guidelines with a recommended set of criteria that manufacturers are expected to use to ensure the systems or devices they provide in their vehicles do not distract the driver with tasks not directly relevant to safely operating the vehicle. Furthermore, the recommended guidelines are clear about IVIS not causing undue distraction by engaging the driver's eyes or hands for more than a very limited duration while driving. Interestingly, electronic warning system functions such as forward-collision or lane departure alerts would not be subject to the proposed guidelines, since they are intended to warn a driver of a potential crash and are not considered distracting devices. It is intended that the guidelines will be progressively phased in - the proposed Phase I distraction guidelines include recommendations to:

- Reduce complexity and task length required by the device;

- Limit device operation to one hand only (leaving the other hand to remain on the steering wheel to control the vehicle);

- Limit individual off-road glances required for device operation to no more than $2 \mathrm{~s}$ in duration.

The last recommendation is particularly relevant to this study since it has been postulated that glances totaling more than $2 \mathrm{~s}$ for any purpose increase near-crash/crash risk by at least two times that of normal, baseline driving.

Many in-vehicle Information and Communication Technologies (ICT) are now available on portable navigators and smartphones and the market penetration of these is increasing exponentially [12]. Nevertheless no standards exist which are directly related to the use of such devices in vehicles and there is little published knowledge about their overall impact on driver behaviour and safety. In 2008, a series of pan-European Field Operational Tests (FOTs) designed to collectively assess the impact of functions provided by "nomadic devices" (such as personal navigation devices) on the driving task were initiated. An FOT is a relatively new concept in the field of transport safety research. The Field Operational Test Support Action (FESTA) handbook [13] defines FOTs as "studies undertaken to evaluate a function or functions under normal operating conditions in environments typically encountered by the host vehicle(s) using quasi-experimental methods". Essentially a FOT involves an extensive fieldtesting program which aims to assess the efficiency, quality, robustness and acceptance of ICT solutions for smarter, safer and cleaner and more comfortable transport and travel. Such ICT technologies include (for example) navigation and traffic information systems, advanced driver assistance systems and co-operative vehicle-highway systems. 
The programme for field-testing of nomadic devices was conducted in 8 EU Member States. The United Kingdom operated 2 different test-sites in the midlands of England and each test-site tested different devices. One test-site hosted at Loughborough in the East Midlands of England tested a personal navigation device (PND) (study 1 ) whilst a second testsite hosted at Nuneaton in the West Midlands of England (study 2) tested a green driving support system (GDS). The studies were conducted independently of each other and there were variations in the approach to the analyses. These are highlighted in the results section for each study.

The objective of this study and current paper was to evaluate the effects that driving with a navigation or green-driving advisory system has on glance behaviours during normal realworld driving scenarios in comparison to a control condition. The specific research question addressed was 'Does the device cause distraction?' and this was addressed by the hypothesis 'The duration and/or number of glances to defined areas of the driver's visual scene changes' whilst also determining the number of glances in excess of $2 \mathrm{~s}$.

\section{Methodology}

\subsection{Participants and data capture}

Participants for study 1 were novice users of a PND who had little experience with such devices. A total of 78 participants were recruited from the test-site locality and all completed a long-term FOT (L-FOT) which lasted for a period of 9 months. However, from the 78 participants, a smaller sample of participants $(n=10)$ were selected to participate in a Detailed FOT (D-FOT) involving enhanced data acquisition. The participants (6 male, 4 female) had an average age of $42($ S.D. $=12.9)$ and were selected purely on a willingness-to-participate basis.

Participants for study 2 were novice users of a prototype GDS device who had little experience with such a device. In total 40 participants completed trials for this FOT. Data were excluded for over half of the participants as selection was made on the quality of the video footage for both the baseline and experimental condition trials. In total, data were analysed at an in-depth level for 15 participants (10 male and 5 female). All trials were conducted in daylight which was a constraint of the Data Acquisition System (which required good lighting to operate effectively).

Participants received a financial incentive for taking part in the studies. These were in the form of a one of payment for each D-FOT and staggered payments throughout the L-FOT.

\subsection{Device tested}

Study 1 tested a Blom NDrive G800 device. The NDrive G800 is a personal navigation solution based on Global
Positioning System (GPS) technology. It provides navigation through visual and voice instructions, which includes names of roads and locations, door-to-door navigation and detailed information about points of interest.

Study 2 tested the Foot-LITE device. Foot-LITE is a Smart' driving system which incorporates (GDS) with safety features of Lane Departure Warning (LDW) and Forward Collision Warning (FCW). Foot-LITE provides the driver with feedback and information on Smart driving behaviours in the vehicle in real time via an integrated visual interface presented on a Smartphone. The Smart driving advice offered is based on numerous internal parameters, with data being collected via an adapted lane departure warning camera and On-Board Device (OBD) II port, as well as accelerometer and GPS. In the tests conducted in the study, information was collected on the driver interaction with a display on the Human-Machine Interface (HMI) which provided feedback on aspects such as levels of acceleration/deceleration, lane positioning and departure warning, headway, and gear change advice.

\subsection{Experimental design}

A "within-subjects" experimental design was used for both studies. The participants completed a 'baseline' drive at the outset of the study during which data capture was performed. In study 1 , the subjects were specifically requested to drive a prescribed route of approximately $25 \mathrm{~km}$ and were directed by an experimenter who was present in the front passenger seat. The route contained a combination of urban/rural/mixed road types and a total of 27 junctions. Following this initial drive, these subjects returned to completing the L-FOT and were given the PND to use on a daily basis. After approximately 8 months (verified through subjective data collection via questionnaire), the same 10 subjects were requested to perform the same $25 \mathrm{~km}$ drive but using the navigation device to guide them around the route (the condition phase). The experimenter was also present during this drive but did not give navigation instructions during the second drive.

In study 2, all subjects only participated in the detailed experimental FOT and were asked to drive a prescribed route first without using the Foot-LITE device (baseline) and then some days later, with the Foot-LITE device (condition).

\subsection{Data collection and processing}

In both studies the subjects were asked to drive a vehicle fitted with a RaceTechnology D2 data-logger which captured data on GPS and several vehicle parameters. Vehicle data capture included information on position, speed, accelerations and vehicle operations and was recorded by an on-board GPSbased data logger. All data were recorded at $100 \mathrm{~Hz}$ and synchronised automatically with the video data. 
Video data was captured at both test-sites using 4 configurable video channels. 2 of the video channels captured contextual data from the road environment including the road ahead and the road behind the vehicle. The other 2 cameras were focused on the participant to primarily capture visual behaviour but they also provided an opportunity to record other aspects of driver manual interaction with the system and other vehicle controls.

\subsection{Data processing}

The video data in both studies were reduced to record the glance duration to specific areas in the driver's fields of vision as follows;

- The device being evaluated

- Mirrors - left and right wing mirrors, rear-view mirror

- Driving Equipment - or vehicle controls (instrument panel, gear stick, handbrake etc.)

- Road: Centre - centre of the roadway, which may not always be straight ahead if for example going round corners

- Road: Off-Centre - looking at the road but not centrally, includes side roads, oncoming traffic, traffic signs or nonspecific road glances

- Other - glances other than those specified above e.g., glances to the experimenter, non-driving related invehicle equipment etc.

Data were processed at both test-sites using a combination of software applications including MATLAB, SPSS, SQL and basic DOS scripts.

In study 1, data were captured for all 10 participants for all of the journeys undertaken. However because the objective of the study was to examine changes in visual behaviour that may be evident with use of a PND, the video data were 'clipped' such that only footage of driving manoeuvres through the 10 most complex junctions e.g., traffic volume and junction complexity including signalisation and presence of other road-users were included. The rationale for this was that these were the locations on the route where the driver would be most reliant on the device for successful negotiation through the junction but also were the locations where mental workload and visual demand on the driver elicited by the PND would be at an absolute maximum given that the driver was reliant on the instructions and cues, both auditory and visual, given by the PND.

In study 2 the route was chosen to include sections of motorway, urban and inter-urban driving environments. This was so that the interaction with the green driving function could be assessed in different driving environments. A total of three $8 \mathrm{~min}$ periods of driving were selected for each driver, one period for each road environment. Each participant drove the same route and hence the location of each environment segment was similar, though the exact distance travelled through each segment varied according to the speed at which each subject drove.

\subsection{Data analysis}

Visual behaviour was coded using a 'data reduction' approach and coding taxonomy of visual behaviour similar to that used in the 100-car study [2]. This included the PND or the FootLITE device during the experimental condition. A comparison was then made of the number of glances and glance durations to each of the selected locations within and external to the vehicle in the baseline and experimental conditions. The coding system and method for data reduction employed varied between the two studies; the details are included under the results for each study.

The data collected in study 1 have been analysed using an independent $t$-test for statistical significance between the two driving trials (Baseline, no navigation device and Condition, with navigation device) at the $5 \%$ level.

The data collected in study 2 have been analysed using both an independent $t$-test and an independent F-test for statistical significance at the $5 \%$ level.

\section{Results}

\subsection{Study 1 (personal navigation device)}

The video data was examined frame by frame for 10 junctions and coded according to whether the driver was attentive to the road ahead (forward) or to elsewhere (other). Glances to the navigation device were identified separately. The analysis concentrates on the number and duration of glances that were away from the road ahead in order to answer the Hypothesis outlined in the introduction.

Addressing the hypotheses 'The number of glances changes', Fig. 1 illustrates the increase in number of glances between baseline and condition trials. Statistically significant differences $(t=8.235$, d.f. $=8, p<0.001)$ are found between the

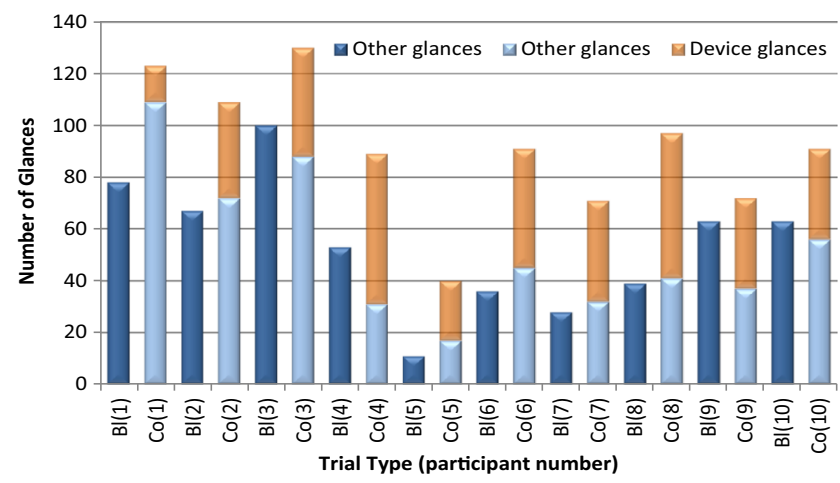

Fig. 1 Number and location of glances across all junctions by baseline (BL) and condition (CO) trial type personal navigation device 


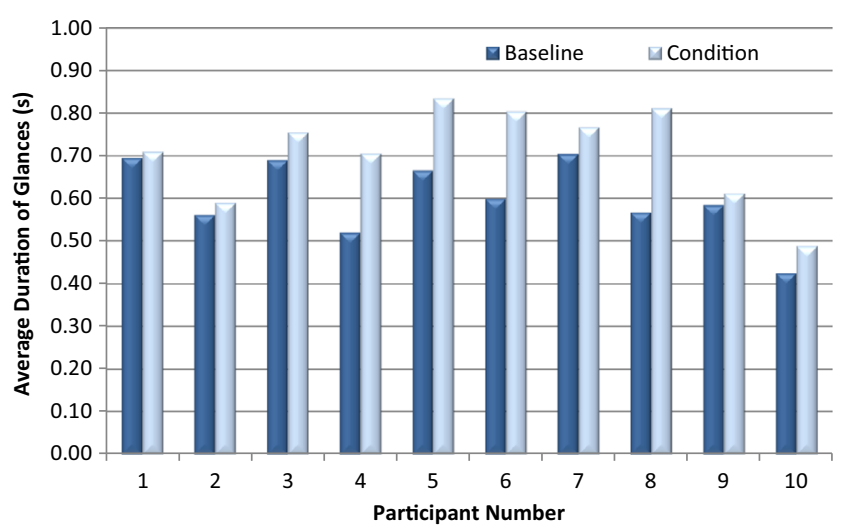

Fig. 2 Average duration of glances across all junctions for baseline and condition trial type personal navigation device

two conditions for all participants with the average increase equating to 37.5 additional glances per participant (the largest increase being 58 additional glances). This is approximately a $100 \%$ increase in number of glances between baseline and condition trials.

The number of glances for all junctions and by experimental condition shows that the increase is predominantly due to glances to the device (Fig. 1). Despite some localised differences the average number of 'other' glances between baseline (BL) and condition (CO) trials remained relatively close at 53.8 glances and 52.8 glances respectively. The number of additional device glances instigated by the effect of the condition trial ranged between 14 and 58 (average 38.5). The increase in the number of glances between baseline and condition is $100 \%$ attributable to the device in 4 participants and $80 \%$ or greater in 5 others, only 1 case shows a lower increase with $31 \%$ of additional glances attributable to the device.

The average duration of glances made during the baseline and condition trials was 0.6 and $0.71 \mathrm{~s}$ respectively (Fig. 2) and this difference was statistically significant $(t=3.25, d . f .=8$, $p<0.01)$. The increase in duration ranged from 0.01 to $0.25 \mathrm{~s}$ (average $0.11 \mathrm{~s}$ increase).

Glances were then separated in to those made during the "Baseline" where no device was present, those made to areas other than the device during the experimental condition when the device was present but not switched on ("Experimental, No Device") and those to the device when it was both present and switched on ("Experimental, Device"). Those made to the test device during the Experimental (Device) trials were generally the longest glances compared to all other locations in both the Baseline and Experimental (No Device) - Fig. 3. However, the difference in average duration of glances between the Baseline and Experimental (No Device) was not significant $(t=1.89, d . f .=8, p=$ n.s. $)$ but the difference in glance duration between the Baseline and the Experimental (Device) condition (specifically average duration of glances to the device) was statistically significant $(t=4.71, d . f .=8, p<0.01)$. The average glance duration to the test device was $0.76 \mathrm{~s}$ compared to the average 'other' durations of 0.60 and $0.65 \mathrm{~s}$ for the Baseline and Experimental (No Device) condition respectively. The greatest increase in glance duration to the device compared to an average of 'other' was $0.31 \mathrm{~s}$, the average increase being $0.13 \mathrm{~s}$.

The majority of glance durations occur between 0.4 and $1 \mathrm{~s}$ (Fig. 4). Glances of longer durations, particularly those over $2 \mathrm{~s}$ do not feature significantly with only small differences between the baseline (BL) and condition (CO) phases (2 glances and 3 glances respectively).

A slight increase in longer glances over $0.8 \mathrm{~s}$ was observed when comparing proportions of all 'other' glances (from baseline and condition trials) with device glances (Fig. 4). An increase in shorter glances was also evident in the 'other' sample while very long glances $(>1.6 \mathrm{~s})$ remained consistent. There is no significant difference in the number of $2 \mathrm{~s}$ glances between the baseline and conditions trials.
Fig. 3 Average duration of glances across all junctions by glance location and trial type personal navigation device

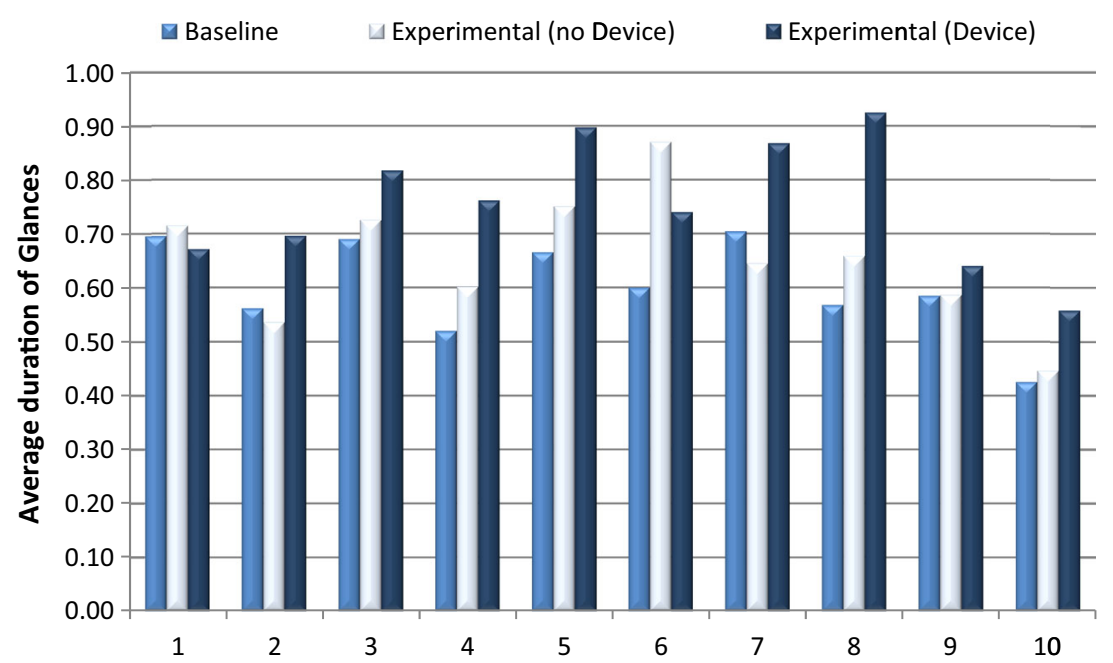




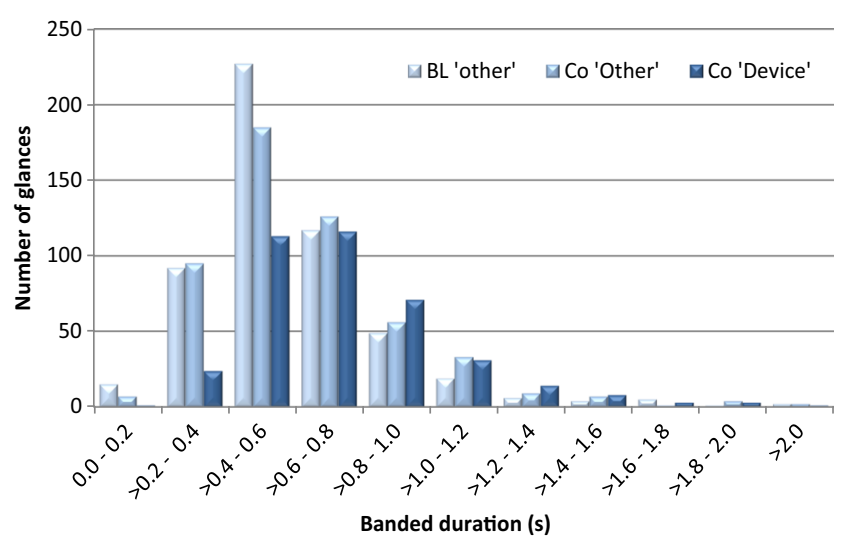

Fig. 4 Number of glances to test device and 'other' locations by glance duration - All trials Personal navigation device

\subsection{Study 2 - green driving advisory device}

Beyond the initial data-processing (as described in the Methodology section above), in order to reduce the video data for the analysis purpose, three $8 \mathrm{~min}$ segments of data were coded. Each segment related to a different road environment; motorway, urban and inter-urban. Thus, 24 min of data were analysed for each participant.

Considering the research question related to the number of glances, the total number of glances (in absolute form) made to any of the locations by the participants was recorded at 1103.3 (S.D. $=130.3)$ glances in the control condition versus $1128.7($ S.D. $=110.9)$ in the experimental condition. Figure 5 below shows the average number of glances made to all locations for each roadway section and there is very little variation.

Certainly there are slightly more glances made during motorway driving (MW) with the device active however this is not true for urban driving (URB) or inter-urban roads (INT) where there is no change and fewer glances respectively. An average for all road types shows this clearly with 368 glances made in the control condition and 367 made during condition (Foot-LITE) driving. Statistical analyses of these data using a students' $t$-test was conducted. Overall the numbers of glances made in the control condition did not differ significantly compared to the numbers of glances made in the experimental condition. Furthermore when the data were analysed according to individual road-types (i.e., motorway, urban and interurban), there was also no difference in the numbers of glances made in the control and experimental conditions.

Using a multi-variate analysis of variance (MANOVA), Fig. 6 below shows that the introduction of the Foot-LITE system resulted in a significant reduction $\left(F_{(1,29)}=12.8\right.$, $p<0.01)$ in the percentage of glances to 'Road Off-centre". This is thought to arise from compensation for glances to the system, which accounted for some $11.4 \%$ of the glances in the experimental condition. No other significant differences were observed.

In respect of the duration of the glances, the mean glance durations to various locations in the vehicle are as shown in Table 1 below. The average glance duration to the mirrors and driving equipment (displays) were around $0.5-0.6 \mathrm{~s}$. No significant changes to mean glance duration was detected as a result of using the device on condition (Foot-LITE) trials. Mean glance duration to the Foot-LITE device was recorded as $0.43 \mathrm{~s}(S D=0.08)$ compared to glances to driving equipment $(0.61 \mathrm{~s})$ or mirrors $(0.49 \mathrm{~s})$.

With few changes being observed in average or maximum glance durations, it would be expected that the percentage of total glances to each location would follow similar trends to glance frequencies - that is, in order to 'allocate' visual resource to the Foot-LITE device during the experimental condition, there would be a corresponding reduction in the percentage of glance durations off-centre when compared to the control condition. This was observed in the analysis using a MANOVA with the reduction being significant $\left(F_{(1,29)}=6.25\right.$, $p<0.05$ ) and with no other interactions occurring (Fig. 7).

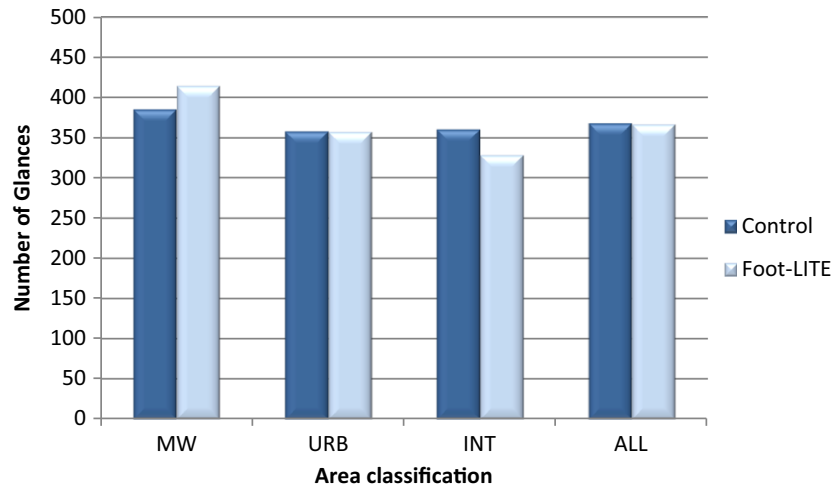

Fig. 5 Total number of glances made for each area class and combined for control condition and Foot-LITE device - green driving advisory device in Motorway (MW), Urban (URB), Interurban (INT) and all roads

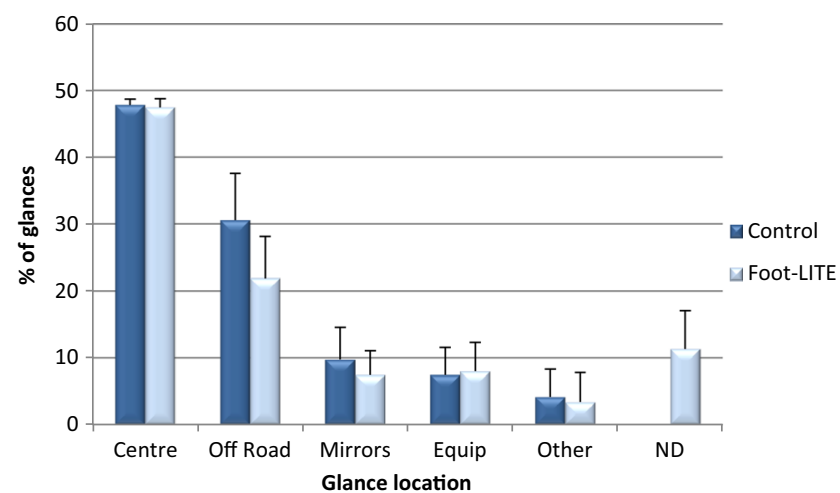

Fig. 6 Mean percentage of glances to each location in the control (no device) and experimental conditions (device present). Error bars represent standard deviations of the mean data - green driving advisory device 
Table 1 Mean number of glances and glance durations for all participants combined from each of 3 roadway sections in control and experimental conditions - green driving advisory device

\begin{tabular}{|c|c|c|c|c|c|c|c|c|c|c|}
\hline & \multicolumn{2}{|c|}{$\%$ of glances } & \multicolumn{2}{|c|}{ Ave glance duration (s) } & \multicolumn{2}{|c|}{$\%$ total glance duration } & \multicolumn{2}{|c|}{ Max glance duration (s) } & \multicolumn{2}{|c|}{ Glances $>2 \mathrm{~s}(\mathrm{n})$} \\
\hline & Control & F-LITE & Control & F-LITE & Control & F-LITE & Control & F-LITE & Control & F-LITE \\
\hline Centre & 47.87 & 47.5 & 2.32 & 2.2 & 77.98 & 77.56 & 19.58 & 18.41 & 158.4 & 156.3 \\
\hline Off road & 30.61 & 21.97 & 0.54 & 0.53 & 12.7 & 9.52 & 4.65 & 5.25 & 5.53 & 5.0 \\
\hline Mirrors & 9.78 & 7.49 & 0.49 & 0.49 & 3.99 & 3.04 & 1.39 & 1.38 & 0.13 & 0.07 \\
\hline Equipment & 7.47 & 8.04 & 0.62 & 0.61 & 3.63 & 3.98 & 1.3 & 1.3 & 0.07 & 0.2 \\
\hline Other & 4.17 & 3.38 & 0.46 & 0.64 & 1.67 & 1.53 & 1.06 & 1.06 & 0.0 & 0.13 \\
\hline Foot-LITE & NA & 11.37 & NA & 0.43 & NA & 4.32 & NA & 1.28 & NA & 0.0 \\
\hline
\end{tabular}

The final parameter examined was the number of glances greater than $2 \mathrm{~s}$ (Fig. 8). Maximum glance durations to locations other than 'centre' (off road, mirrors, driving equipment, other and device) were consistently around 1.3-1.4 s duration. No change to maximum glance duration was observed as a result of using the device on condition trials. The maximum glance duration recorded for the device was $1.3 \mathrm{~s}$.

No glance of greater than $2 \mathrm{~s}$ were made to the device by any of the participants during the $24 \mathrm{~min}$ of the driving scenario selected for this analysis. 6 glances exceeded the 2-s threshold and were recorded to the Driving equipment $(\times 3)$, other $(\times 2)$ and once to the mirrors. $75 \%$ of all glances made during the Foot-LITE trial were between 0.2 and $0.6 \mathrm{~s}$, considerably below the 2 -s threshold.

\section{Discussion}

In this study, the results of the FOTs for the navigation device, study 1 , showed that the device led to an increase in both the percentage of eyes of road time and the average glance duration. In some respects, a change in visual behavior is to be expected since the navigation device provides information,

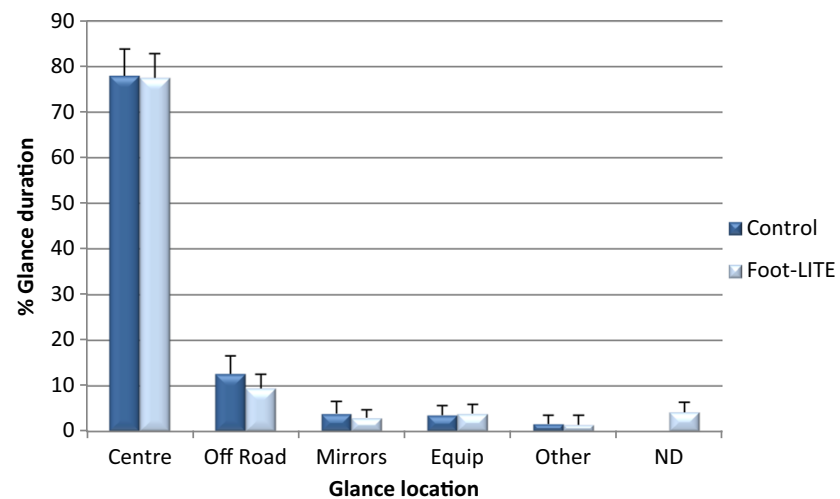

Fig. 7 Mean percentage of glance durations to each location in the control and experimental conditions (Error bars represent the standard deviation of the data) - green driving advisory device both auditory and visual, which is designed to be processed by the driver in order to significantly facilitate the driving task. However, it is necessary to examine whether this change in visual behavior is detrimental to safety by distracting the driver from focusing fully on the driving task.

One could argue that any additional eyes off road time beyond that required to safely operate the vehicle in accordance with for example the rules laid out for the driving test (rear view mirror, side mirror checks etc.) is intuitively negative in terms of safety, however, as introduced previously, relationships have been suggested between the length of glances away from the road and the risk of accident involvement. However, these relationships also need to be contextualised with vehicle speed and complexity of road environment which also influence crash risk.

In study 1 , the percentage of eyes off road tine for drivers was much greater in the experimental (with device) condition compared to the baseline condition ( $14.3 \%$ compared to $6.7 \%$ ) but further analysis of the glance behaviour shows that whilst glances to the personal navigation device account for the majority of the increase in eyes off road time (in accordance with intuitive expectations), when the durations of the glances are analysed, there are very few which are $2 \mathrm{~s}$ or more in duration and the average glance is $0.76 \mathrm{~s}$ which compared with average duration of glances to other target areas of $0.6 \mathrm{~s}$, well below the proposed NHTSA guidelines.

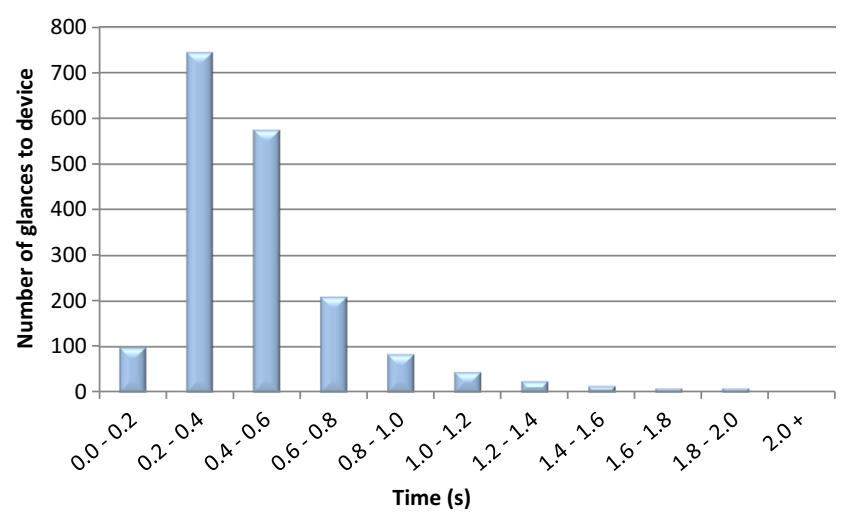

Fig. 8 Number of glances to foot-LITE device by banded glance duration 
In study 2 , the main outcome was that the total number of glances made was similar for each condition, at approximately 1100. Therefore glances to the in-vehicle GDS system during the experimental condition must have been reallocated from a different location. Mean glance duration to the Foot-LITE device was $0.43 \mathrm{~s}$, with approximately $75 \%$ of the glances being between 0.2 and $0.6 \mathrm{~s}-$ also well below the NHTSA proposed guidelines.

Although there were a few glances over $2 \mathrm{~s}$ in either FOT, these occurred both to the navigation and equally to other areas of the visual scene, the $2 \mathrm{~s}$ guide is a rough rule of double risk which needs to be contextualised further with vehicle speed and complexity of road environment which influence crash risk.

It is difficult to compare the results of the Navigation tests with the Foot-LITE tests. For one thing, the HMIs are different as is the response expected from the driver with the Foot-LITE HMI being associated with a simple driver response (speed up, slow down etc.) whereas navigation requires more cognitive processing to interpret the information provided in order to make an appropriate response. Other devices with a diversity of HMI's may provide wider ranging and perhaps different results. Furthermore, the market is evolving quickly and even moved on during the life of the project. There is now more widespread use of smart-phone applications to provide functions, an example of a change in HMI. Hence although the results of this study are useful on the assumption that they could be more widely extrapolated to the general traffic context, there is a need to keep evaluating how the changing HMI's affect driver distraction. However, comparing this with other research which has investigated the effects of using an IVIS on glance behaviours, shows that time recorded with Foot-LITE was considerably less in comparison. Other studies of mean glance durations to PNDs have been shown to be between 1.06 and $1.45 \mathrm{~s}$ [14] and approximately $1 \mathrm{~s}$ [15] whilst glances to in car entertainment were found to be $0.88 \mathrm{~s}$ [16] and between 0.8 and $1.1 \mathrm{~s}$ [14].

Small sample size particularly was an issue in this study and further studies should aim to use larger samples where possible as well as automating the data analysis process. It should also be remembered that in both FOTs, it was only possible to examine segments of the drive to address the Distraction question. For a more comprehensive evaluation, it would have been necessary to examine on a frame-by-frame basis all of the video data for all of the individual drivers in all of the tests. However, with the available resources and project duration, it was only possible to analyse the video data for a sample of participants for which visual behaviour data was available. For these drivers, it was also only possible to select certain segments of the route driven. Whilst every effort was made to ensure that the segments (road junctions) that were chosen were both the most demanding in a visual and cognitive workload sense and where reliance on the nomadic device was high (and hence whether the risk of distraction was thought to be at its maximum), the fact remains that the sample size is small overall and nothing can be learned regarding the driving during other segments of the route. Although an initial attempt was made to overcome this dilemma by automating the visual data collection process (using eye-tacking equipment) this was not successful as it became apparent that the version of eye-tracking equipment used, which normally works extremely well in carefully controlled laboratory environments did not work well in the situations in this study where the environment is very variable and changes rapidly (due to differential lighting). As this technology has been significantly improved in recent times, it is unlikely that this same problem would be evident with a more state-of-the-art eye-tracking device.

\section{Conclusions}

- In this study, glances to a Personal Navigation Device were found to account for the majority of the increase in eyes off road time (in accordance with intuitive expectations)

- When the durations of the glances were analysed, there were very few which were $2 \mathrm{~s}$ or more in duration. The average glance was $0.76 \mathrm{~s}$ which compared with average duration of glances to other target areas of $0.6 \mathrm{~s}$.

- Furthermore, the total number of glances made to an invehicle Smart driving system was similar for each tested condition, at approximately 1100 . Therefore glances to the system during the experimental condition must have been reallocated from a different location.

- $\quad$ Around $75 \%$ of the glances were between 0.2 and $0.6 \mathrm{~s}$.

- However, any increase in eyes off-road time should give cause for concern and future smart in-vehicle systems should consider a design limiting the user to auditory interface only when complex road situations arise.

Open Access This article is distributed under the terms of the Creative Commons Attribution 4.0 International License (http:// creativecommons.org/licenses/by/4.0/), which permits unrestricted use, distribution, and reproduction in any medium, provided you give appropriate credit to the original author(s) and the source, provide a link to the Creative Commons license, and indicate if changes were made.

\section{References}

1. Hedlund J, Simpson H, Mayhew D (2006) International conference on distracted driving: summary of proceeding and recommendations, page 6. Ottawa: TIRF and CAA. The Traffic Injury Research Foundation and Canadian Automobile Association, Toronto

2. Klauer SG, Dingus TA, Neale VL, Sudweeks JD, Ramsey DJ (2006) The impact of driver inattention on near-crash/crash risk: an analysis using the 100-car naturalistic driving study. National Highway Traffic Safety Administration (NHTSA), Washington D.C, Report No: DOT HS 810594 
3. Pettitt M, Burnett G, Stevens A (2005) In proceedings of the 12th ITS world congress. ITS America, San Francisco, USA, Defining Driver Distraction

4. Gordon CP (2008) Crash studies of driver distraction. In: Regan M (ed) Driver distraction: theory, effects and mitigation. CRC Press, Taylor and Francis Group, Boca Raton, pp 281-304

5. Caird JK, Dewar RE (2007) Driver distraction. In: Dewar RE, Olson PL (eds) Human factors in traffic safety, 2nd edn. Lawyers and Judges Publishing, Tucson, AZ, pp 195-229

6. Olson R, Hanowski RJ, Hickman JS, Bocanegra J (2009) Driver distraction in commercial vehicle operation. Report No FMCSARRR-09-042, UD Department of Transportation

7. Regan MA, Lee JD, Young KL (2009) Driver distraction; theory, effects and Mitigation. Taylor and Francis, ISBN 13:978-0-84937426-5, CRC press

8. NHTSA (2006) The impact of driver inattention on crash risk: an analysis using the 100-car naturalistic driving study, national highway safety administration, Report No. DOT HS 810594

9. Sussman ED, Bishop H, Madnick B, Walter R (1985) Driver inattention and highway safety. Transp Res Rec 1047:40-48, Transportation Research Board

10. Wang JS, Knipling RR, Goodman MJ (1996) The role of driver inattention in crashes - New statistics from the 1996
Crashworthiness data system. 40th Annual Proceedings of the Association of the Advancement of Automotive Medicine; Vancouver British Columbia 377-382

11. United States Department for Transportation Press Release (2012. http://www.dot.gov/briefing-room/us-department-transportationproposes- $\%$ E2\%80\%98distraction $\%$ E2\%80\%99-guidelinesautomakers

12. Mononen P, Franzen SER, Pagle K, Morris AP, Fruttaldo S, Montanari R (2010) TeleFOT, field operational tests of aftermarket nomadic devices in vehicles, early results. In Proceedings of 17 th ITS World Congress, 25-29 October, ITSW 2010, Busan, South Korea, pp.1-10

13. Field Operational Test Support Action (FESTA) Handbook Version 2 (2008) FESTA consortium, european commission

14. Dingus T, Antin J, Hulse M, Wierwille W (1989) Attentional demand of an automobile moving-map navigation system. Transp Res A 23:301-315

15. Green P, Hoekstra E, Williams M, Wen C, George K (1993) Examination of a videotape-based method to evaluate the usability of route guidance and traffic information systems. Univ Mich Transp Res Inst Tech Rep UMTRI 93(31):1-90

16. Lansdown T (2000) Driver visual allocation and the introduction of intelligent transport systems. Proc Inst Mech Eng D 214:645-652 